\title{
EDUCAÇÃO E POLÍTICAS PÚBLICAS PARA A PROTEÇÃO DA CRIANÇA E DO ADOLESCENTE NO CONTEXTO BRASILEIRO
}

\author{
EDUCACIÓN Y POLÍTICAS PÚBLICAS PARA LA PROTECCIÓN DEL NIÑO Y DEL \\ ADOLESCENTE EN EL CONTEXTO BRASILEÑO
}

\section{EDUCATION AND PUBLIC POLICIES FOR THE PROTECTION OF CHILDREN AND ADOLESCENTS IN THE BRAZILIAN CONTEX}

\author{
Tânia Mara MINETTO ${ }^{1}$ \\ Cênio Back WEYH ${ }^{2}$
}

RESUMO: O artigo emerge de dissertação desenvolvida no Programa de pós-graduação em Educação da URI - Campus de Frederico Westphalen, tendo como pano de fundo a constituição das políticas públicas e os direitos da criança e do adolescente no Brasil. As discussões são resultado de investigação empírica e teórica, tendo por área de abrangência a violência na escola e o papel da rede de proteção social no acesso aos direitos da criança e do adolescente. Buscou-se percorrer os marcos históricos, legais e conceituais que nortearam os debates da trajetória histórica das políticas públicas, investigações acerca da violência na escola e a constituição dos direitos da criança e do adolescente. O recorte histórico situa-se na década de 1980, quando as pesquisas sobre violência e escola emergem com consistência. Quanto aos aspectos legais buscou-se elucidar as primeiras legislações da proteção da infância e juventude, e a jornada até o Estatuto da Criança e do Adolescente. O enfoque da violação dos direitos da criança e do adolescente abrange família e sociedade, e a forma de organização das políticas públicas no contexto contemporâneo. Constatou-se que ainda vivemos o dilema da dicotomia teoria e prática, no campo da inefetividade, quando se trata de ação dos preceitos legais, o que fundamentalmente torna-se um problema político e não legal. Portanto, é na política municipal de proteção aos direitos da criança e do adolescente com base no tripé plano, fundo e conselho que serão projetadas ações com base operacional para a garantia dos direitos humanos da criança e do adolescente.

PALAVRAS-CHAVE: Políticas públicas. Rede de proteção social. Criança e adolescente. Violência escolar.

RESUMEM: El artículo emerge de disertación desarrollada en el Posgrado en Educación de la URI - Frederico Westphalen, teniendo como pantalla la constitución de las políticas públicas y los derechos del niño y del adolescente en Brasil. Las discusiones resultan de investigación empírica y teórica sobre la violencia en la escuela y el papel de la red de

${ }^{1}$ Universidade Regional Integrada do Alto Uruguai e das Missões (URI), Erechim - RS - Brasil. Mestre em Educação .PPG em Educação. Assessora de empresas. ORCID: http://orcid.org/0000-0002-5836-1584. E-mail: minetto.taniamara@gmail.com

${ }^{2}$ Universidade Regional Integrada do Alto Uruguai e das Missões (URI), Erechim - RS - Brasil. Doutor em Educação; docente do curso de Pedagogia e do PPG Mestrado Profissional em Ensino Científico e Tecnológico. Líder do Grupo de Pesquisa: "Estudos Pedagógicos e Formação Docente”. ORCID: http://orcid.org/0000-00019333-4170. E-mail: ceniow@ santoangelo.uri.br

RIAEE - Revista Ibero-Americana de Estudos em Educação, Araraquara, v. 14, n. 4, p. 2123-2140, out./dez., 2019. E-ISSN: 1982-5587. 
protección social en los derechos del niño y del adolescente. Se ha recorrido marcos históricos, legales y conceptuales que orientan debates sobre la trayectoria de las políticas públicas, investigaciones sobre violencia escolar y la constitución de los derechos del niño y del adolescente. El recorte histórico está en la década de 1980, cuando emergen consistentemente investigaciones sobre violencia y escuela. Sobre los aspectos legales, se buscó elucidar las primeras legislaciones de protección de la infancia y juventud, y la jornada hasta el Estatuto del Niño y del Adolescente. El enfoque para la violación de los derechos del niño y del adolescente abarcan familia, sociedad, y las políticas públicas contemporáneas. Se ha constatado que todavía vivimos el dilema de la dicotomía entre teoría y práctica, en el campo da inefectividad cuando se trata de acción de los preceptos legales, lo que resulta un problema político y no legal. Por tanto, es en la política municipal de protección a los derechos del niño y del adolescente con base en la trípode plan, fondo y consejo que se proyectarán acciones con base operacional para la garantía de los derechos humanos del niño y del adolescente.

PALABRAS-CLAVE: Políticas públicas. Red de protección social. Niño y adolescente. Violencia escolar.

ABSTRACT: The article emerges from a dissertation developed in the Post-Graduation Program in Education of the URI-Campus of Frederico Westphalen, having as background the constitution of public policies and the rights of children and adolescents in Brazil. The discussions are the result of empirical and theoretical research, covering violence in school and the role of the social protection network in accessing the rights of children and adolescents. It was sought to go through the historical, legal and conceptual frameworks that guided the debates of the historical trajectory of public policies, investigations about violence in the school and the constitution of the rights of the child and the adolescent. The historical cut is in the 1980s, when polls on violence and school emerge with consistency. As for the legal aspects, it was sought to elucidate the first laws of the protection of children and youth, and the journey to the Statute of the Child and Adolescent. The focus of the violation of the rights of children and adolescents encompasses family and society, and the organization of public policies in the contemporary context. It was found that we still live the dilemma of the dichotomy theory and practice, in the field of ineffectiveness when it comes to action of legal precepts, which fundamentally becomes a political problem and not legal. Therefore, it is in the municipal policy for the protection of the rights of children and adolescents based on the tripod plan, fund and council that will be projected actions with operational base to guarantee the human rights of the child and the adolescent.

KEYWORDS: Public policies. Social protection network. Child and teenager. School violence.

\section{Introdução}

Os Direitos da Criança e do Adolescente têm mobilizado a sociedade civil, movimentos sociais, profissionais, crianças e adolescentes e organizações governamentais a lutar por uma legislação que garanta, minimamente, os direitos humanos básicos. A história denota que os direitos foram constituídos tendo por referência as lutas contra a violência 
vivida por crianças e adolescentes que estavam desprotegidos, seja pela legislação como pelas políticas públicas que na época eram inexistentes.

Refletir sobre os direitos da criança e do adolescente, a violência na escola e o papel da rede de proteção social para o acesso a esses direitos, nos levou a dar enfoque para a violação dos direitos da criança e do adolescente que não se situam num campo específico, mas abrangem desde a família e a sociedade, bem como a forma de organização das políticas públicas no contexto contemporâneo.

Levando-se em consideração esses aspectos, a violência vai tomando formas e expressões de acordo com a evolução da sociedade: se num momento histórico estavam desprotegidas pela legislação e pelas políticas públicas, hoje constatamos desproteção pela inoperância desses pressupostos legais. As transformações rápidas e intensas mudam o desenho do ser humano de relacionar-se e de interagir com a sociedade. Assim, a percepção fragmentada do mundo e do seu entorno, a fragilidade das relações familiares, sociais e comunitárias, abrem espaço e dão visibilidade à violência.

A vulnerabilidade dos direitos humanos está se apresentando como objeto de pesquisa e de reflexões das mais diversas áreas do conhecimento. Sendo um fenômeno complexo, multicausal e de difícil definição, o tema violência vem sendo estudado por profissionais como assistentes sociais, educadores, sociólogos, antropólogos, psicólogos entre outros.

No que se refere à área da educação escolar, a violência tem assumido expressões cada vez mais profundas e importantes. Considerando-se que este é o segundo espaço de socialização, seguido da instituição família, e que é permeado de diferenças sociais, culturais, econômicas e de contextos familiares, entende-se que é um espaço privilegiado de investigação.

A quebra paradigmática que o ECA provocou levou muitos profissionais, ONGS, judiciário, Ministério Público, Polícia Civil, Militar, Federal e Rodoviária, Escolas, dentre outros, a buscar novos conhecimentos e conceitos para intervir junto à criança e ao adolescente. Essa imersão leva a uma atuação na base operacional da política da criança e do adolescente, com a implantação de programas e projetos que ofereçam cobertura à proteção e prevenção à criança e ao adolescente em nível municipal. Dessa forma, o sonho de construir uma política municipal e articulada para a proteção aos direitos da criança e do adolescente nas três esferas do governo, e com a rede de serviços em pleno funcionamento, começa a tornar-se realidade. Além disso, as articulações entre sociedade civil e governo vão aprofundando-se em busca da construção de uma política de proteção às crianças e aos adolescentes do Brasil de qualquer ação nociva ao seu pleno desenvolvimento. 
Contudo, um dos maiores entraves para que essas mudanças aconteçam e para que haja de fato, uma quebra paradigmática em relação à política de proteção à criança e ao adolescente, com todas as mudanças jurídico-conceituais, é a questão cultural, ainda o maior desafio a ser enfrentado.

As diretrizes da Política Nacional dos Direitos da Criança e do Adolescente preveem a construção de um conjunto articulado de ações nas áreas da saúde, educação, assistência social, trabalho, habitação, entre outros. Houve avanços inclusive nas discussões para implantação e implementação da rede de proteção em nível de prevenção. Como exemplo disso, é possível citar o SUS e a Assistência Social, com ações efetivas e centradas na proteção e prevenção à violência infanto-juvenil.

$\mathrm{Na}$ revisão de literatura buscou-se trazer as reflexões sobre os direitos fundamentais, evolução e composição para a proteção da criança e do adolescente, bem como a sua relação com o contexto escolar. Nesta parte do artigo procurar-se-á caracterizar a historicidade e o significado dos direitos fundamentais, direitos humanos, família, violência doméstica na perspectiva dos direitos humanos e educação. A sustentabilidade teórico-conceitual encontrase em autores como: Arendt (1978; 1994), Benevides (2000), Bobbio (2000; 2004), Freire (1997), Kant (2004), dentre outros que discutem os direitos humanos, especialmente aqueles relacionados à proteção da criança e do adolescente.

As reflexões acerca da instituição das políticas públicas e sua transversalidade com temas afins teve o foco voltado para a violência na perspectiva dos direitos humanos, políticas públicas na prevenção da violência e a garantia dos direitos da criança e do adolescente. As discussões acenam para o papel da escola na proteção e prevenção da violência e na garantia dos direitos fundamentais. As principais bibliografias estão fundamentadas em Bourdieu (1982), Deslandes (1994), Faleiros (2006), Saviani (2003), Sêda (2002), Haddad (2003), Minayo (1993, 2001), Waiselfisz (1998, 2008). A discussão é fecunda e oportuna, uma vez que o tema da violência no espaço de convivência familiar e suas repercussões no espaço escolar podem contribuir e motivar a comunidade escolar a se munir de alternativas para a garantia dos direitos da criança e do adolescente, independente do espaço onde ocorreu a violência. 


\section{Políticas públicas para a proteção da criança e do adolescente no Brasil: aspectos históricos}

Os registros de políticas públicas de proteção à infância e adolescência desenvolvidas pelo Estado brasileiro datam do início do século XX. As instituições de caridade, como as Santas Casas, coordenadas pela Igreja Católica, responsabilizavam-se em atender doentes e órfãos de famílias economicamente destituídas de bens. Importou-se da Europa no século XVIII um sistema de recolhimento de donativos e de acolhimento de crianças abandonadas, denominado de Roda dos Expostos. A Roda constituía-se de um cilindro oco de madeira que girava em torno do próprio eixo com a abertura em um dos lados, inserida numa abertura semelhante a uma janela para que se colocassem as crianças, bem como os donativos. Esse modelo privilegiava o anonimato, especialmente das mães, que não dispunham de recursos para cuidar de seus filhos, bem como das mães solteiras que, para os padrões da época não poderiam assumir, publicamente, a maternidade. Contudo, já nesta época as mães eram obrigadas a registrar seus filhos (MARCÍLIO, 2001).

A regulamentação da obrigatoriedade do ensino só aconteceu em 1854, contudo não foi universalizada, uma vez que os filhos de escravos, os que padeciam de moléstias contagiosas e aqueles que não tivessem sido vacinados não poderiam acessar o sistema de ensino. $\mathrm{O}$ atendimento à saúde não priorizava todas as classes sociais, as crianças advindas de famílias pobres não tinham acesso às vacinas, e consequentemente não lhes era permitido frequentar a escola. Constata-se aqui uma dupla exclusão aos direitos sociais, o não acesso ao atendimento à saúde gerando restrição à educação.

Outra preocupação constante relacionava-se ao decreto $\mathrm{n}^{\circ}$. 1.313, de 1891 , o qual determinava a idade mínima de 12 anos para o trabalho. No entanto, há registros históricos que, na prática, a lei não tinha efetividade: num momento de expansão das indústrias e da agricultura a mão de obra infantil era necessária e utilizada sem precedentes. Contudo, a politização do proletariado não custou a acontecer, as lutas sociais no século XX foram um marco para que os trabalhadores pudessem discutir e ter direitos sociais e trabalhistas. Durante a greve geral de 1917, liderada por trabalhadores urbanos, é criado o Comitê de defesa do proletariado. Das suas reivindicações consta a proibição do trabalho de menores de 14 anos de idade e a abolição do trabalho noturno de mulheres e de menores de 18 anos. Mais que uma reivindicação, denota a denúncia de violação dos direitos humanos em relação à criança e ao adolescente, bem como à mulher, que padeciam de jornadas de trabalho de até 14 horas diárias. 
Posteriormente a esse movimento, em 1923, foi instituído o Juizado de Menores, sendo que o Juiz Mello Mattos foi o primeiro juiz de menores da América Latina. Em 1927, o Código de Menores, também conhecido popularmente como Código Mello Mattos, é o primeiro documento legal para a população com menos de 18 anos de idade. A base de atuação da referida lei centrava-se naquelas crianças, reconhecidamente em situação irregular, definindo já em seu Artigo $1^{\circ}$, a quem a lei se aplicava: "O menor, de um ou outro sexo, abandonado ou delinquente, que tiver menos de 18 anos de idade, será submetido pela autoridade competente às medidas de assistência e proteção contidas neste Código" (p. 22).

As diretrizes são claras de que a lei dispõe exclusivamente ao trato da infância e juventude, regulamentando questões como trabalho infantil, tutela e pátrio poder, delinquência e liberdade vigiada. Ao juiz cabia o poder do destino de muitas crianças e adolescentes, as quais não eram ouvidas, mas tinham julgadas suas causas de acordo com os princípios do juiz.

O período conhecido como Estado Novo, que vigorou entre 1937 e 1945, na arena social, foi marcado pela instituição de um aparato executor das políticas sociais no país. Podemos destacar a legislação trabalhista, a obrigatoriedade do ensino e a cobertura previdenciária, associadas à inserção profissional. A grande crítica centrava-se por seu caráter não ser universal, restringindo-se aos trabalhadores que tinham carteira assinada; no campo conceitual, Santos (1994) denominou por cidadania regulada. O amparo de forma universal foi reconhecido nesta época como um direito político de indivíduos excluídos até então, como as mulheres.

Em 1942, período considerado autoritário do Estado Novo, foi criado o Serviço de Assistência ao Menor - SAM. Tratava-se de um órgão do Ministério da Justiça, funcionando como um equivalente do sistema Penitenciário para a população menor de idade. Sua orientação era correcional-repressiva. O sistema previa atendimento diferenciado para o adolescente autor de ato infracional e para o menor carente e abandonado. Embora ambos fossem considerados em situação irregular, ao primeiro cabia o encaminhamento para internatos, conhecidos também como reformatórios e casas de correção; o menor carente e abandonado era encaminhado aos patronatos e escolas de aprendizagem de ofícios urbanos.

Outras poucas entidades federais de atenção à criança e ao adolescente foram criadas, contudo, eram ligadas à figura da primeira dama do governo federal. Os programas desenvolvidos tinham por objetivo o campo do trabalho, tendo como prática o assistencialismo vigente na época, como a LBA - Legião Brasileira de Assistência - agência nacional de assistência social, que foi criada por Dona Darcy Vargas. Intitulada originalmente 
de Legião de Caridade Darcy Vargas, a instituição era voltada, primeiramente, ao atendimento de crianças órfãs da guerra, expandindo seu atendimento posteriormente; Casa do Pequeno Jornaleiro: programa de apoio a jovens de baixa renda, baseado no trabalho informal e no apoio assistencial e socioeducativo; Casa do Pequeno Lavrador: programa de assistência e aprendizagem rural para crianças e adolescentes filhos de camponeses; Casa do Pequeno Trabalhador: Programa de capacitação e encaminhamento ao trabalho de crianças e adolescentes urbanos de baixa renda e Casa das Meninas: programa de apoio assistencial e socioeducativo a adolescentes do sexo feminino com problemas de conduta (IAMAMOTO, 1983).

Com a deposição do Governo Vargas em 1945, tem-se a promulgação da quarta Constituição em 1946. De caráter liberal, esta constituição simbolizou a volta das instituições democráticas. Restabeleceu a independência entre o Executivo, Legislativo e Judiciário, o pluripartidarismo, a eleição direta para presidente (com mandato de cinco anos), a liberdade sindical e o direito de greve. Esta constituição acaba com a censura e a pena de morte no Brasil (IAMAMOTO, 1983).

Em 1950, foi instalado o primeiro escritório do UNICEF no Brasil, em João Pessoa, na Paraíba. O primeiro projeto realizado no Brasil destinou-se às iniciativas de proteção à saúde da criança e da gestante em alguns Estados do nordeste do país.

O período de 1945 a 1964 foi marcado pela coexistência do aprofundamento das conquistas sociais em relação à população de baixa renda e o controle da mobilização e organização, que surge aos poucos, nas comunidades. A opinião pública começa a ver o SAM como repressivo e desumano, conhecido como 'universidade do crime'. A década de 1960 é marcada pela organização da sociedade civil e um cenário internacional polarizado pela guerra fria, denotando necessidade de posicionar-se.

Em 1964, o Golpe Militar posiciona o Brasil no panorama internacional, colocando-o em linha com os países capitalistas. Com a instituição da ditadura militar, foi interrompida a democracia no país por mais de duas décadas. A nova Constituição, elaborada em 1967, estabeleceu diferentes diretrizes para a vida civil e o autoritarismo do Estado tornou-se uma realidade. Com restrições à liberdade de opinião e expressão, recuos no campo dos direitos sociais e instituição dos Atos Institucionais, que permitiam punições, exclusões e marginalizações políticas foram algumas das medidas que esta nova ordem trazia ao Brasil.

A visão dos governos militares também incidiu sobre a área da infância, instituindo a Lei n. 4.513 , de $1^{\circ}$ de dezembro de 1964, que criou a Fundação Nacional do Bem-Estar do Menor. Seu principal objetivo centrava-se em formular e implantar a Política Nacional do 
Bem-Estar do Menor, herdando do SAM estrutura física e recursos humanos e, também, toda a sua cultura organizacional. Denominada como FUNABEM, propunha-se a ser a grande instituição de assistência à infância, tendo como linha de ação a internação, tanto dos abandonados e carentes, como dos infratores, sendo estes últimos seu principal foco (IAMAMOTO, 1983)

A Lei 6.697, de 10 de outubro de 1979, constituiu-se em uma revisão do Código de Menores, de 1927. Contudo, não rompe com sua linha de arbitrariedade, assistencialismo e repressão para com a população infanto-juvenil. Nesse momento histórico tem-se a introdução do conceito de "menor em situação irregular", referindo-se a meninos e meninas que estavam dentro do que alguns autores denominam infância em "perigo" e "infância perigosa", considerada objeto principal da administração da Justiça de Menores. É conferida à autoridade judiciária, nesta legislação, poderes ilimitados para o trato e o destino da população infantojuvenil. (VOGEL, 2009).

O reconhecimento pela Declaração sobre os Direitos da Criança (1959), da criança e do adolescente como sujeito de direitos garantidos a toda pessoa humana, e demais direitos essenciais conferidos em resultado da tenra idade e da sua situação peculiar de desenvolvimento (MELO, 2010), apresenta-se nesse período como um ganho inestimável no que se refere às conquistas do direito da criança e do adolescente. Segundo Bobbio (1992, p. 35): “A Declaração dos Direitos da Criança apresenta o problema dos direitos da criança como uma especificação da solução dada ao problema dos direitos do homem".

Contudo, as repercussões da Declaração dos Direitos da Criança, no ordenamento jurídico brasileiro, aconteceram de forma incipiente e tímida, fato que pode ser relacionado a estrutura que o governo militar havia implantado ao final da década de 1960 e na década de 1970. Nos primeiros movimentos para o restabelecimento da democracia no Brasil, constataram-se indícios de movimento social pelos direitos da criança e juventude no Brasil. Naves (2004) aponta que nesse período tem-se uma grande ampliação de todas as formas de repressão social no Brasil, e diante da situação dramática vivida pela infância brasileira, o movimento de luta pelos direitos da infância e juventude logo passou a ser expressivo.

A Academia, através de seus pesquisadores, também assume seu papel nesse contexto, e a partir de meados da década de 1970, surgem interessados em estudar a população em situação de risco, principalmente a situação da criança de rua e o denominado delinquente juvenil. Notadamente, as discussões em relação aos problemas relacionados à infância e à adolescência, no interior das universidades, apresentavam-se como uma forma de alavancar discussões sobre políticas públicas e direitos humanos. 
As pesquisas que se destacaram tiveram por tema a inquietante situação de rua e a delinquência juvenil no Brasil. Entre as pesquisas de maior destaque cita-se: "A criança, o adolescente, a cidade": pesquisa realizada pelo CEBRAP - São Paulo, em 1974; "Menino de rua: expectativas e valores de menores marginalizados, em São Paulo": pesquisa realizada por Rosa Maria Fischer, em 1979; "Condições de reintegração psicossocial do delinquente juvenil; estudo de caso na Grande São Paulo": tese de mestrado de Virginia P. Hollaender pela PUC/SP, em 1979; “O Dilema do Decente Malandro”, tese de mestrado, defendida por Maria Lucia Violante, em 1981, publicada, posteriormente, pela Editora Cortez.

As discussões acerca dos direitos humanos a nível mundial, conforme Bobbio (1992), repercutiram na legislação brasileira no que se refere à infância e à juventude. Ainda a mobilização internacional para o desenvolvimento dos direitos do homem teve influência direta nos preceitos institucionais quanto aos direitos auferidos na constituição de 1988.

Para os direitos da criança e do adolescente, a década de 1980 foi considerada um marco histórico. O movimento pelos direitos da criança e juventude nesta década provocou debates no meio acadêmico, em organizações de classe e no meio empresarial, resultando em uma ampla gama de direitos e garantias aos menores de 18 anos de idade (NAVES, 2004).

Somados às pesquisas, os movimentos sociais e a mobilização nacional e internacional de órgãos com interesse na defesa dos direitos humanos, especialmente aos da infância e adolescência, para o Estatuto da Criança e do Adolescente, foram importantes na década de 1980, com a abertura democrática no Brasil, a qual se materializou pela promulgação da Constituição da República Federativa do Brasil de 1988, denominada Constituição Cidadã. O processo de redemocratização do país representou para a infância e juventude importantes e decisivas conquistas.

Contudo, temos um duelo em torno do tema infância e adolescência: os menoristas que defendiam a manutenção do Código de Menores e os estatutistas que defendiam uma grande mudança no Código de Menores, instituindo novos e amplos direitos às crianças e aos adolescentes, que passariam a ser sujeitos de direitos e a contar com uma Política de Proteção Integral. Em relação a este último grupo havia uma exímia articulação, com representação e capacidade de atuação na esfera nacional.

Das estratégias utilizadas para a incorporação de uma nova visão sobre a infância e a juventude na nova carta constitucional, tornou-se necessário mobilizar antes mesmo das eleições parlamentares constituintes, e assumir compromissos públicos com a causa dos direitos da infância e da adolescência. 
A Assembleia Nacional Constituinte (1987) era composta por 559 congressistas e durou 18 meses. Em cinco de outubro de 1988, foi, então, promulgada a Constituição Brasileira, que, marcada por avanços na área social, introduziu um novo modelo de gestão das políticas sociais, que conta com a participação ativa das comunidades através dos conselhos deliberativos e consultivos.

$\mathrm{Na}$ Assembleia Constituinte organizou-se um grupo de trabalho comprometido com o tema da criança e do adolescente, cujo resultado se concretizou no artigo 227, que introduz conteúdo e enfoque próprios da Doutrina de Proteção Integral da Organização das Nações Unidas, trazendo os avanços da normativa internacional para a população infanto-juvenil brasileira. Este artigo garantia às crianças e aos adolescentes os direitos fundamentais de sobrevivência, desenvolvimento pessoal, social, integridade física, psicológica e moral, além de protegê-los de forma especial, ou seja, através de dispositivos legais diferenciados, contra negligência, maus tratos, violência, exploração, crueldade e opressão.

Além do artigo 227 da CF 1988 ter sido base para a construção do Estatuto da Criança e do Adolescente, a Comissão de Redação teve representação de três grupos, sendo estes o dos movimentos da sociedade civil, o dos juristas, especialmente aqueles ligados ao Ministério Público, e os representantes de técnicos de órgãos governamentais, funcionários da FUNABEM.

Pode-se afirmar que a década de 1980 foi, em nível mundial, extremamente profícua em termos de defesa dos direitos da criança e do adolescente. Entidades e movimentos sociais surgiram e foram fundamentais para a construção da legislação vigente, no caso do Brasil, o ECA. No início deste período, não ao acaso, mas pelas concretas denúncias de crianças e adolescentes vitimizadas pela tortura, abandono, maus tratos, ou seja, abandonadas à própria sorte e sem cobertura de políticas públicas que as protegessem, o clamor por proteção não poderia mais ficar sem resposta.

Em termos nacionais merecem destaque o Movimento Nacional dos Meninos e Meninas de Rua (MNMMR), que surgiu em 1985 em São Bernardo do Campo, um importante centro sindical do país, e a Pastoral da Criança, criada em 1983, em nome da CNBB - Conferência Nacional dos Bispos do Brasil, com forte militância em defesa dos direitos da criança e do adolescente, proveniente dos movimentos sociais da igreja católica. Com o advento do ECA (Lei 8.069/90), em 13 de Julho de 1990, consolidaram-se os anseios da sociedade brasileira com a produção de um documento de direitos humanos que contemplaria o que há de mais avançado na normativa internacional em respeito aos direitos da população infanto-juvenil, em contrapartida com a intervenção arbitrária do Estado na vida 
de crianças e adolescentes. A partir desse momento, a luta centra-se pela efetivação do ECA e na mudança da cultura do adulto em miniatura para criança e adolescente, de assujeitado para sujeito de direitos.

O artigo 227 da Constituição Federal de 1988, bem como o ECA, introduziram um novo conceito, munindo-se de orientações científicas acerca do desenvolvimento biopsicossocial do ser humano, considerando criança aquele sujeito de zero até doze anos e o adolescente de 12 anos de idade aos dezoito anos, excepcionalmente aos 21 anos de idade. As lutas em prol dos direitos da criança e do adolescente assumem um novo horizonte, o de buscar sua implementação e avançar na construção de uma política pública efetiva que garanta a interlocução entre os diversos atores, principalmente os que estão na base de operação dessas políticas nos âmbitos governamental e não governamental.

É indiscutível, ainda, o desenvolvimento e organização da sociedade civil e sua participação na arena político nacional e internacional, dando vazão para o crescimento do terceiro setor, bem como sua participação na operacionalização e físcalização junto às políticas sociais, especialmente na área da infância e juventude. A constituição do tripé Conselho de Direitos, Fundo e Plano nas três esferas do governo, uma das diretrizes da política de atendimento apregoada na lei, tem como protagonistas da formulação de políticas para a infância e juventude um grupo formado, paritariamente, por membros representantes da sociedade civil e de instituições governamentais.

O ECA ainda representa um grande desafio para os brasileiros militantes e comprometidos com a garantia e defesa dos direitos da criança e do adolescente. Ainda há muito que avançar para a implantação e implementação dos dispositivos legais desta legislação.

Embora os avanços em relação às políticas públicas tenham sido significativos, considerando a história brasileira, notadamente marcada mais pelo autoritarismo que pelo fortalecimento de instituições democráticas, a luta pelos direitos humanos no Brasil permanece pela persistência de cidadãos que acreditam e lutam por um mundo justo e igualitário. Infelizmente não pode ser dito o mesmo em relação à atuação do parlamento brasileiro, especialmente no momento atual, em que há uma tendência virulenta de desconstituição de direitos sociais, capitaneada por uma equipe de governo de tendência liberal conservadora. 


\section{Os direitos e a composição para os direitos essenciais à pessoa humana: aspectos teóricos}

A questão da justiça e igualdade nos reporta para os direitos essenciais à pessoa humana que emergem no desenvolvimento da civilização, quando a humanidade vivenciou uma diversidade de períodos com suas especificidades. Dessa mesma forma, evoluíram a ciência, a tecnologia, as políticas, a economia, os direitos, bem como as relações sociais. É nesse contexto que os direitos inerentes à pessoa humana foram construídos, de forma lenta e gradual, a partir da vivência e experiência da vida em sociedade.

A gênese desses direitos encontramos na Idade Antiga, passando pela Idade Média e Moderna, donde tem-se elementos fundadores para a construção dos direitos humanos. Ressalta-se, também, a influência de revoluções, como a inglesa, a francesa e a americana no reconhecimento e na positivação dos direitos essenciais à pessoa humana, na busca de um mundo mais justo e igualitário. Contudo, neste artigo não pretendemos resgatar essas construções históricas e teóricas. Os direitos humanos são resultantes de pesquisas acadêmicas e bases teóricas, mas principalmente, de lutas contra o poder. Bobbio (1992, p. 05) afirma que "os direitos do homem, são direitos historicamente construídos a partir de lutas e enfrentamento a velhos poderes, emergindo de forma gradual".

Canotilho (2004, p. 9) referenda as discussões de Bobbio ao destacar que os direitos humanos localizam-se na história política, atraindo, de forma global, "as ideias, o imaginário, a ideologia dominante, a consciência coletiva, a ordem simbólica e a cultura política”.

$\mathrm{O}$ surgimento dos direitos essenciais à pessoa humana emerge de lutas contra a opressão, ao desmando e ao poder dominante, a partir de condições propícias e reconhecimento da necessidade que garanta aos indivíduos e à sociedade uma existência digna.

Ao denominar direitos essenciais à pessoa humana, referimo-nos aos direitos naturais, públicos subjetivos, liberdades públicas, direitos morais, direitos dos povos, direitos humanos e direitos fundamentais. Neste trabalho beneficiar-se-á das duas últimas expressões, sendo que os direitos humanos denotam os direitos antes da positivação pelas constituições, e os direitos fundamentais para identificar o seu reconhecimento dentro de um ordenamento jurídico específico. Não se trata de reducionismo jurídico, mas de buscar a forma mais ampla possível sem causar prejuízos de reconhecimento aos direitos humanos. Dessa forma, busca-se analisar o significado conceitual e a relação existente entre direitos humanos e direitos fundamentais. O termo 'direitos humanos' é amplo e as doutrinas acerca dos direitos humanos e fundamentais serão tratadas aqui como sinônimos. 
O conceito de direitos humanos passa pelo reconhecimento de sua dimensão histórica, do seu processo de construção ao longo da história da evolução da humanidade, bem como das transformações da vida política, industrial, econômica, ou seja, na arena de atuação humana.

Benevides (2009) destaca que os direitos humanos são aqueles direitos comuns a todos os seres humanos, sem distinção de raça, sexo, classe social, religião, etnia, cidadania política ou julgamento moral. Esses direitos decorrem do reconhecimento da dignidade intrínseca a todo ser humano. Independem do reconhecimento formal dos poderes públicos - por isso, são considerados naturais ou acima e antes da lei -, porém necessitam da garantia desses poderes.

Nessa mesma linha de pensamento, Trindade (1992) refere que os direitos humanos operam, especificamente, na defesa intransigente dos mais fracos ou mais vulneráveis em relação à proteção. Inspira-se, ainda, nos preceitos da ordre public, salvaguardando os interesses superiores da promoção da justiça. A evolução histórica e os avanços dos direitos humanos se devem ao enfrentamento de todos os tipos de dominação, opressão e exclusão, especialmente por parte da sociedade civil. Como exemplo, constata-se que as normas jurídicas não interpretadas e aplicadas almejando sempre a proteção de supostas vítimas.

Portanto, a neutralidade dos direitos humanos inexiste, estes sempre asseguram proteger, promover e zelar pela dignidade do ser humano. $\mathrm{O}$ desrespeito à pessoa humana significa desrespeitar a humanidade como um todo. Convém lembrar ainda que os direitos humanos são inerentes à própria condição humana, e seu reconhecimento é resultado de um processo histórico de lutas contra o poder, a fim de dar uma melhor direção para a humanidade.

Dessa forma é que a germinação dos direitos fundamentais acontece pelo processo de positivação dos direitos humanos, que decorre do reconhecimento e das legislações positivas de direitos considerados inerentes à pessoa humana.

As expressões direitos do homem e direitos fundamentais são frequentemente utilizadas como sinônimas. Segundo a sua origem e significado poderíamos distingui-las da seguinte maneira: direitos do homem são direitos válidos para todos os povos e em todos os tempos; direitos fundamentais são os direitos do homem, jurídico-institucionalmente garantidos e limitados espaço-temporalmente. Os direitos do homem arrancariam da própria natureza humana e daí o seu caráter inviolável, intertemporal e universal; os direitos fundamentais seriam os direitos objetivamente vigentes numa ordem jurídica concreta (CANOTILHO, 1998, p. 259). 
A doutrina jurídica tem utilizado a expressão dos direitos humanos para identificar os direitos inerentes à pessoa humana na ordem internacional, para os ordenamentos jurídicos específicos. Utiliza-se a expressão direitos fundamentais, os quais estão relacionados ao reconhecimento dos direitos diante de um poder político, e devidamente reconhecido por normas constitucionais de um Estado.

[...] o termo direitos fundamentais se aplica para aqueles direitos do ser humano reconhecidos e positivados na esfera do direito constitucional positivo de determinado Estado, ao passo que a expressão direitos humanos guardaria relação com os documentos de direito internacional, por referir-se àquelas posições jurídicas que se reconhecem ao ser humano como tal, independentemente de sua vinculação com determinada ordem constitucional, e que, portanto aspiram à validade universal, para todos os povos e tempos, de tal sorte que revelam um inequívoca caráter supranacional (SARLET, 2005, p. 35-36).

Ao considerarmos esses aspectos pode-se concluir que a expressão direitos humanos é utilizada para designar o momento histórico que estes surgiram ou foram reconhecidos pela humanidade, e a expressão direitos fundamentais denota a positivação destes direitos. A internacionalização dos direitos humanos e fundamentais acontece em 10 de dezembro de 1948, após sua aprovação pela Assembleia Geral das Nações Unidas em Paris.

A relevância que os direitos fundamentais passam a ter na esfera internacional e no ordenamento jurídico de cada Estado está na perspectiva da necessidade: a equidade tem presença concreta na franquia dos direitos fundamentais, objetivando a prevalência da liberdade individual.

Contudo, há que rememorar junto à história a origem desse importante ganho jurídico institucional. A Declaração dos Direitos do Homem foi apresentada em 26 de agosto de 1789, na França. Este documento tem uma relação íntima com a revolução francesa. $\mathrm{O}$ tema direitos tinha uma valoração inestimável para os revolucionários, bem como a urgência em revelar a declaração, objetivando a legitimação do governo que assumira o poder após o afastamento do rei Luís XVI. O exercício do poder deveria estar fundamentado em princípios que justificassem e conduzissem legisladores e governantes.

A Declaração de 1789, tida como fonte de inspiração, foi precursora na defesa dos direitos humanos. Em seu artigo primeiro, a Declaração de Direitos do Homem e do Cidadão, de 1789, diz: "Os homens nascem e permanecem livres e iguais em direitos. As distinções sociais só podem fundar-se na utilidade comum". Observa-se aqui a inspiração no lema da República francesa: liberdade, igualdade e fraternidade. 
No mesmo artigo da Declaração Universal dos Direitos Humanos de 1948, há uma ampliação em relação aos direitos. "Todos os homens nascem primeiro livres e iguais em dignidade e direitos. São dotados de razão e consciência e devem agir em relação uns aos outros com espírito de fraternidade”. Percebe-se aqui a centralidade nos direitos civis para a garantia da liberdade individual e nos direitos políticos, referente à igualdade de participação política.

No entanto, há ainda uma luta incessante para usufruir desse rol de direitos, sejam de ordem nacional ou internacional, mesmo que estejam explícitos em documentos legais. Entraves culturais e político-econômicos devem ser suplantados. Entretanto, aspectos da cultura de um povo transformam-se com pequenas ações no cotidiano: é nesse cotidiano que vamos colocando em prática os preceitos jurídicos legais e garantindo à população excluída seus direitos.

\section{Considerações finais}

Neste trabalho foi destacado que houve, ao longo da história, uma construção consistente de legislação e de políticas públicas para a proteção da infância e adolescência. No entanto, crianças e adolescentes ainda estão à mercê da violência, que tem adquirido novas e intensas formas, como bullying, tráfico de seres humanos, drogadição, trabalho infantojuvenil, prostituição, além de outras violações. Por isso, ainda buscamos formas de proteger integralmente a criança e o adolescente, melhorando as políticas públicas através da rede de proteção, tendo por referência a legislação, que vem sendo aperfeiçoada.

Ressaltamos que o exercício da cidadania por crianças e adolescentes ainda é uma promessa distante de ser cumprida. A Constituição de 1988, bem como o Estatuto da Criança e do Adolescente, no seu compromisso em criar uma política que de fato e de direito proteja esse segmento, ainda vivem a promessa de uma belíssima legislação, e de um futuro promissor de proteger crianças e adolescentes que vivem em situação de desproteção. Desta forma, o seu futuro pode estar sendo comprometido justamente pela ausência de políticas públicas efetivas no que se refere aos direitos humanos de crianças e adolescentes.

Vivemos ainda o dilema da dicotomia teoria e prática, que está no campo da inefetividade quando se trata de ação de fato dos preceitos legais, o que fundamentalmente torna-se um problema político e não legal. Assim, há a necessidade de viabilizar formas para buscar a concretude desse direito, que perpassa pelo rol das políticas públicas. É na política municipal de proteção aos direitos da criança e do adolescente, com base no tripé Plano, 
Fundo e Conselho, que serão projetadas ações com base operacional para a garantia dos direitos humanos da criança e do adolescente.

Um dos objetivos para este trabalho era provocar uma reflexão crítica sobre a evolução da legislação e das políticas de proteção à criança e ao adolescente, e explicitar o quão ainda somos incapazes de operacionalizá-las. Em âmbito geral, vale destacar que as nossas críticas concentram menos sobre aspectos da legislação e políticas públicas, para focar o olhar mais crítico para a base operacional, sua consistência em termos de organização, material humano, na transversalidade das políticas, e no diálogo entre os diversos atores da política da criança e do adolescente e das demais políticas públicas.

\section{REFERÊNCIAS}

ARENDT, H. Entre o Passado e o Futuro. São Paulo: Perspectiva. 1978.

ARENDT, H. Da Violência. Rio de Janeiro: Vozes. 1994.

BENEVIDES, M. V. de M. (org.). Direitos humanos, democracia e república. São Paulo: Quartier Latin. 2009.

BOBBIO, N. O futuro da democracia. 9. ed. Trad. Marco Aurélio Nogueira. São Paulo: Paz e Terra, 2000.

BOBBIO, N. Thomas Hobbes. Trad. Carlos Nelson Coutinho. Rio de Janeiro: Campus, 2004.

BOBBIO, N.; COUTINHO, C. N. (Trad.). A era dos direitos. Rio de Janeiro: Campus, 1992.

BOURDIEU, P.; PASSERON, J. C. A reprodução: Elementos para uma teoria do sistema de ensino. Trad. de Reynaldo Bairão. Rio de Janeiro: Francisco Alves, 1982.

BRASIL. Código de menores. Disponível em:

http://www.planalto.gov.br/ccivil_03/decreto/1910-1929/d17943a.htm.

BRASIL. Constituição da República Federativa do Brasil. 1988.

BRASIL. Estatuto da Criança e do Adolescente. Lei Federal n. 8069 de 13 de julho de 1990.

CANÇADO TRINDADE, A. A. Tratado de Direito Internacional dos Direitos Humanos. Volume II. Porto Alegre: Sergio Fabris Editor. 1999.

CANOTILHO, J. J. G. Direito Constitucional e Teoria da Constituição. 3 ed. Coimbra: Almedina, 1998. 
CANOTILHO, J. J. G. Estudos sobre Direitos Fundamentais. Coimbra: Coimbra Editora, 2004.

DECLARAÇÃO DOS DIREITOS DO HOMEM E DO CIDADÃO, 1789. Disponível em: http://webcache.googleusercontent.com/search?q=cache:gbARPWjs1tUJ:pfdc.pgr.mpf.mp.br/ atuacao-e-conteudos-de-apoio/legislacao/direitos.

DESLANDES, S. F. Prevenir a violência - um desafio para profissionais de saúde. Rio de Janeiro: FIOCRUZ/ENSP/CLAVES, 1994.

FALEIROS, V. de P. Formação de educadores (as): subsídios para atuar no enfrentamento à violência contra crianças e adolescentes. Brasília: MEC/SECAD. Florianópolis: UFSC/SEaD, 2006.

FREIRE, P. Política e educação. São Paulo: Cortez, 1997.

HADDAD, S. Educação de Jovens e Adultos, a promoção da cidadania ativa e o desenvolvimento de uma consciência e uma cultura de paz e direitos humanos. Mimeo. 2003.

IAMAMOTO, M. V.; CARVALHO, R. Relações Sociais e Serviço Social no Brasil: esboço de uma interpretação histórico-metodológica. 2. Ed. São Paulo: Cortez, 1983.

KANT, I. Fundamentação da metafísica dos costumes. Tradução de Paulo Quintela. Lisboa: Edições 70, 2004.

MELO, M. A. B. de. Direito das Coisas. 3. Edição. Editora Lumen Juris. Rio de Janeiro, 2009.

MINAYO, M. C. S.; SOUZA, E. R. Violência para todos. Cadernos de Saúde Pública - 9, Rio de Janeiro, 1993.

MINAYO, M. C. S. Violência contra crianças e adolescentes: Questão social, questão de saúde. Revista Brasileira de Saúde Materno infantil, n. 1(2), p. 91-102. 2001.

NAVES, R. Justiça para crianças e jovens. In: Práticas de Cidadania. Organização: Jaime Pinsky. São Paulo: Contexto, 2004.

SANTOS, W. G. dos. Razões da Desordem. Rio de Janeiro: Rocco, 1994.

SARLET, I. W. A eficácia dos direitos fundamentais. 6. ed. Porto Alegre: Livraria do Advogado, 2006.

SAVIANI, D. Pedagogia histórico-crítica: primeiras aproximações. 8. ed. Campinas, São Paulo: Autores Associados, 2003. (Col. Educação contemporânea).

TRINDADE, A. L.; SANTOS, R. Multiculturalismo: mil e uma faces da escola. Rio de Janeiro: DP\&A. 1999. 
TRIVIÑOS, A. N. S. Introdução à pesquisa em ciências sociais: a pesquisa qualitativa em Educação. São Paulo: Atlas, 1987.

UNESCO. Panorama mundial do direito. O Correio da Unesco. 2000.

VOGEL, A. Do Estado ao Estatuto. Propostas e vicissitudes da política de atendimento à infância e adolescência no Brasil contemporâneo. In: RIZZINI, I.; PILOTTI, F. A arte de governar crianças: a história das políticas sociais, da legislação e da assistência à infância no Brasil. 2. ed. São Paulo: Ed. Cortez, 2009.

WAISELFISZ, J. Juventude, Violência e Cidadania: os Jovens de Brasília. Brasília: Unesco e Cortez, 1998.

WAISELFISZ, J. J. Mapa da Violência dos Munícipios Brasileiros. Ideal gráfica e Editora. 1. ed., 2008.

\section{Como referenciar este artigo}

WEYH, Cênio Back; MINETTO, Tânia Mara. Educação e políticas públicas para a proteção da criança e do adolescente no contexto brasileiro Revista Ibero-Americana de Estudos em Educação, Araraquara, v. 14, n. 4, p. 2123-2140, out./dez., 2019. E-ISSN: 1982-5587. DOI: https://doi.org/10.21723/riaee.v14i4.9920

Data de Submissão: 27/05/2019

Revisões requeridas: 20/07/2019

Aceite em: 27/07/2019

Publicado em: 02/09/2019 